\title{
JOGOS E ATIVIDADES LÚDICAS NA PRÁTICA DE INICIAÇÃO À DOCÊNCIA EM QUÍMICA: UM ESTUDO NO SUBPROJETO QUÍMICA SEDE DO PIBID/UFRPE
}

André Guimarães Carneiro ${ }^{1}$

Maria do Rocio Fontoura Teixeira ${ }^{2}$

\begin{abstract}
RESUMO: Este artigo teve como objetivo realizar um levantamento dos jogos utilizados pelos bolsistas do subprojeto de Química (sede do PIBID/UFRPE), como ferramenta de auxílio nos processos de ensino-aprendizagem. Para tanto, foram analisados os relatórios de atividades do projeto no período de março de 2014 a fevereiro de 2018, através dos aportes da análise de conteúdo. Observou-se que os jogos puderam ser utilizados a partir de estratégias variadas, porém, com ênfase na revisão dos conceitos abordados. Os materiais utilizados variaram, desde os materiais de baixo custo até o uso de jogos online.
\end{abstract}

Palavras-Chave: Jogos; Lúdico; Química; PIBID.

ABSTRACT: This article aimed to carry out a survey of the games used by the fellows of the Chemistry subproject (headquarters of PIBID / UFRPE), as an aid tool in the teaching-learning process. To this end, the project activity reports from March 2014 to February 2018 were analyzed through content analysis. It was observed that the games could be used from different strategies, however, with an emphasis on reviewing the concepts covered. The materials used varied, from low-cost materials to the use of online games.

Keywords: Games; Ludic; Chemistry Teaching.

\section{Introdução}

Este estudo faz parte de uma pesquisa de mestrado em Ensino de Ciências que abordou o uso de jogos e atividades lúdicas na área do Ensino das Ciências da Natureza, realizada no âmbito do Programa Institucional de Bolsas de Iniciação à Docência (PIBID), da Universidade Federal Rural de Pernambuco - UFRPE.

O PIBID, instituído em 2007, pela Portaria Normativa n. 38 - do Ministério da Educação (MEC), oferecia bolsas de iniciação à docência aos licenciandos de cursos presenciais das Instituições de Ensino Superior, que se dedicassem ao estágio nas escolas públicas e que se comprometessem com o exercício do magistério na rede pública depois de graduados. As áreas prioritárias para o ensino médio eram nesta ordem: as licenciaturas em Física, Química, Matemática e Biologia, nas quais se nota a menor presença de professores em exercício com formação específica. Para o ensino médio e para os anos finais do ensino fundamental, as áreas prioritárias eram: as licenciaturas em Ciências e

Técnico em Assuntos Educacionais, Universidade Federal Rural de Pernambuco. Contato: andreguimaraes177@gmail.com

2 Professora do Programa de Pós-Graduação Educação em Ciências, Universidade Federal do Rio Grande do Sul. 
Matemática e, de forma complementar, as licenciaturas em Letras (língua portuguesa), Música, Artes e demais.

De acordo com Silva et al. (2017), quando começou o PIBID na UFRPE em 2009, o projeto contemplava, além das quatro licenciaturas consideradas prioritárias pelo edital (Biologia, Física, Matemática e Química), a Licenciatura em Ciências Agrárias, em Computação e em História. Foi criado então um projeto de natureza interdisciplinar, com o eixo temático denominado "Ciência e Contexto: letramento científico na educação básica". Com a expansão da Universidade e do programa, o PIBID passou a contemplar outras licenciaturas e, a partir de 2010, foram incluídos os cursos de Letras e Pedagogia na sede e na Unidade Acadêmica de Garanhuns/PE, além de Letras e Química na Unidade Acadêmica de Serra Talhada/PE. Em 2011, foi incluída a Licenciatura em Educação Física da sede, assim, o PIBID/UFRPE passou a contemplar todas as 14 licenciaturas existentes na universidade.

As atividades do subprojeto Química (sede do PIBID/UFRPE), objeto específico de análise deste artigo, integraram, entre os anos de 2014 e 2017, as ações de 103 bolsistas de iniciação à docência em sete escolas da rede pública estadual de ensino e uma escola vinculada à UFRPE, todas localizadas no Recife e região metropolitana.

Em atendimento ao estabelecido no regulamento PIBID/CAPES, publicado na Portaria n. 096/2013, foi criado o regimento interno do Programa, aprovado pela Resolução 163/2014 do Conselho de Ensino, Pesquisa e Extensão da UFRPE. Este regimento teve por objetivo orientar todos os participantes do PIBID quanto as suas atuações no programa, além de reforçar os objetivos traçados pela CAPES.

O regimento interno traz também os critérios de seleção e acompanhamento das escolas participantes, assim como da equipe do programa no âmbito da Universidade. Ainda, de acordo com o referido regimento, a avaliação dos membros do PIBID deve ser realizada pela Comissão de Acompanhamento do PIBID (CAP) "mediante análise de relatórios de atividades contendo a descrição das principais ações realizadas e em andamento". De acordo com o parágrafo $1^{\circ}$, Art. 22, os relatórios de atividades dos projetos são convertidos em relatórios parciais, que seriam então, encaminhados à CAP a cada seis meses. Já o relatório final deveria ser encaminhado à CAP até 30 dias após o encerramento da vigência do projeto. É de incumbência da CAP, aprovar os relatórios internos antes de encaminhá-los à CAPES.

Ao analisarmos os relatórios do PIBID/UFRPE, observamos que os jogos e atividades lúdicas representam uma perspectiva relevante no ensino das Ciências da Natureza, tendo em vista que estes foram bastante contemplados entre os anos de 2014 e 2017 nos subprojetos de Biologia, Física e Química. Entretanto, apenas o subprojeto Química do campus sede foi analisado no âmbito desta pesquisa. 


\section{Jogos na Educação}

Brincar pode possibilitar excelentes oportunidades para o ensino e aprendizagem. O ser humano precisa brincar como forma de diversão, interação, desenvolvimento da criatividade e, também, para estudar. Segundo Heloysa Dantas, citada em Kishimoto (1998), brincar e jogar são dois termos distintos em português onde, "brincar é anterior a jogar, conduta social que supõe regras" (p. 111).

Kishimoto (2002), aponta o que denomina "paradoxo do jogo educativo", que se expressa pela presença concomitante de duas funções, a saber:

1. função lúdica: o jogo propicia diversão, o prazer e até o desprazer quando escolhido voluntariamente, e; 2 . função educativa - o jogo ensina qualquer coisa que complete o indivíduo em seu saber, seus conhecimentos e sua compreensão do mundo (KISHIMOTO, 2002, p. 19).

Para a referida autora, o equilíbrio entre as duas funções é o objetivo do jogo educativo e a ação pedagógica dos professores deveria respeitar a liberdade de brincar da criança, pautando-se na organização do espaço, na seleção dos brinquedos e na interação com os alunos. $O$ jogo educativo ganha, assim, dois sentidos:

1. sentido amplo: como material ou situação que permite a livre exploração em recintos organizados pelo professor, visando ao desenvolvimento geral da criança e; 2. sentido restrito: como material ou situação que exige ações orientadas com vistas a aquisição ou treino de conteúdos específicos ou de habilidades intelectuais. No segundo caso recebe, também, o nome de jogo didático (KISHIMOTO, 2003, p. 22).

Sendo assim, se utilizado em seu sentido amplo, o jogo educativo exerce função de formação geral e, se utilizado em seu sentido restrito, exerce a função de auxiliar o ensino de conteúdos específicos, levando-nos a inferir que todo jogo é educativo.

Cunha (2012) define e diferencia os termos "jogo educativo" e "jogo didático" ao afirmar que:

O primeiro envolve ações ativas e dinâmicas, permitindo amplas ações na esfera corporal, cognitiva, afetiva e social do estudante, ações essas orientadas pelo professor, podendo ocorrer em diversos locais. O segundo é aquele que está diretamente relacionado ao ensino de conceitos e/ou conteúdos, organizado com regras e atividades programadas e que mantém um equilíbrio entre a função lúdica e a função educativa do jogo, sendo, em geral, realizado na sala de aula ou no laboratório (CUNHA, 2012, p. 95).

Para o referido autor, ao escolher um jogo, o professor deveria considerar o aspecto motivacional deste para com a turma, ou seja, equilibrar o aspecto lúdico e o educativo e, considerar ainda o aspecto da coerência que é relacionado às regras, aos objetivos pedagógicos e ao material utilizado para o desenvolvimento dos jogos com os alunos. Nesse sentido, fica clara a importância do planejamento sistematizado para o uso dos jogos didáticos. 
Soares $(2004,2010)$ também enfatiza a importância do equilíbrio entre as funções lúdica e educativa para o uso eficaz de jogos pelos professores. Porém, ao diferenciar jogo didático e jogo educativo Soares et al. (2018) incluem na discussão a categoria do jogo pedagógico e defendem que o jogo didático e o jogo pedagógico são ramificações de uma subcategoria do jogo educativo que, por sua vez, pode ser classificado como jogo educativo informal ou jogo educativo formalizado o qual abrange os jogos didáticos e jogos pedagógicos. Os autores explicam que:

o jogo educativo pode ser informal como o conhecemos mais de perto e que se aproxima do sentido strictu do jogo, mas também pode ser formalizado, carregando a intenção pedagógica de quem o propõe ou, melhor, promover aprendizagens de conceitos/ conteúdos formais e materializados a alguém (SOARES et al., 2018, p. 37).

Dessa forma, eles definem os jogos didáticos como "um tipo de jogo educativo formalizado, adaptado a partir de um jogo educativo informal e que teve conteúdos didáticos de uma determinada área de conhecimento ancorados em seu escopo" (Idem, p. 39).

Considerando que - desde o início de suas atividades - o PIBID vem produzindo várias experiências relacionadas ao uso de jogos e atividades lúdicas no ensino dos mais variados temas ligados à área de Ciências da Natureza, considerando a educação básica por todo o país, e, à luz do conceito de jogos educativos proposto por Soares, explicitado acima, buscamos neste trabalho desenvolver um levantamento dos jogos utilizados pelos bolsistas do subprojeto Química - campus sede da UFRPE, como ferramenta de auxílio nos processos de ensino-aprendizagem.

\section{Caminho metodológico}

Trata-se de uma pesquisa descritiva, pois pretende descrever o uso de jogos no ensino de Química no PIBID/UFRPE. A abordagem adotada foi quanti-qualitativa, por entendermos que esta é aquela que melhor se adequa ao nosso objetivo. Uma abordagem apenas quantitativa não daria conta de captar as experiências analisadas neste estudo; já a abordagem qualitativa, preocupa-se com os sentidos e significados das ações dos bolsistas quanto ao uso de jogos numa perspectiva compreensiva e interpretativa.

Partindo da pesquisa documental, examinou-se os relatórios de atividades do PIBID/UFRPE, entre março de 2014 e fevereiro de 2018, período de vigência do Edital n. 061/2013 - CAPES, que selecionou os projetos institucionais para participação no programa. Tais relatórios constituem uma compilação de todas as atividades realizadas pelos bolsistas, com periodicidade anual. Por isso, considerando que o tema principal deste estudo se refere ao uso dos jogos na área do ensino das Ciências da Natureza no PIBID, esses relatórios nos pareceram documentos apropriados para a análise dos jogos utilizados, já que a produção gerada estava relatada nesses documentos. 
Para a avaliação dos relatórios, utilizou-se a análise de conteúdo proposta por Bardin (1977). Assim, como sugere a autora, realizamos uma leitura detalhada dos documentos e adotamos um processo organizado de codificação e categorização das ações voltadas para o uso de jogos, no referido subprojeto. Para tanto, observamos que as atividades estão divididas nos relatórios em cinco categorias propostas pela CAPES:

- Produções didático-pedagógicas onde podem se enquadrar produtos como banners e cartazes pedagógicos produzidos, criação de banco de imagens, criação de banco de sons, criação de Blogs, criação de kits de experimentação, estratégias e sequências didáticas, folders, mapas conceituais, mídias e materiais eletrônicos, planos de aula, Plataforma Moodle e outras, (Wikipédia), preparação de aulas e estratégias didáticas, preparação de estratégias e sequências didáticas para o Portal do Professor, preparação de minicursos, produção de cadernos didáticos, produção de objetos de aprendizagem, produção de roteiros experimentais, produção de softwares, projetos educacionais realizados, sínteses e análises didáticas; outros;

- Produções bibliográficas que podem incluir produtos como artigo técnico-científico publicado; dissertação de mestrado em andamento ou concluída; edição, organização e/ou coordenação de livros ou coleções; publicação de jornais na escola; publicação de livro; publicação de capítulo de livro; publicação de resumo técnico-científico; publicação de trabalho completo; publicação individual de crítica e resenha científico-educacional ou prefácio de obras especializadas ou espetáculos; tese de doutorado em andamento ou concluída; trabalho de conclusão de curso em andamento ou concluída; tradução de capítulo de livro; tradução de peças teatrais, de óperas encenadas e livros; outros;

- Produções artístico-culturais que englobam produtos como adaptação de peças teatrais; atividades de grafitagem, atividades de leitura dramática e/ou peça radiofônica; atividades de restauração de obras artísticas; autoria de peças teatrais, roteiros, óperas, concertos, composições musicais, trilha sonora, cenografia, figurino, iluminação e/ou coreografia integrais apresentadas ou gravadas nas IES e escolas participantes; criação de espetáculos de dança; criação de filmes e atividades cênicas; criação de grupos musicais; criação de rádio escolar; desenho e pintura; exposição artístico-educacional; exposição de fotos e imagens; festivais de dança na escola; festivais de música; maquetes; transcrição e/ou arranjos de obras musicais; participação de alunos em concertos, recitais ou gravações; participação de alunos em peças teatrais; sarau escolar, vernissage, dentre outros;

- Produções desportivas e lúdicas que incluem atividades como criação de times de modalidades esportivas (basquete, vôlei, futebol, etc), competições esportivas, criação de materiais para recreação; criação de rodas de capoeira; desenvolvimento de novas modalidades esportivas na escola; gincanas escolares; jogos para recreação e socialização; jogos inter-classes; desenvolvimento de jogos especiais para inclusão (goalball, futebol de 7, futebol de 5, voleibol sentado, natação, bocha, outros); jogos populares; jogos dos povos indígenas (arco e flecha, cabo de força, corrida de tora, natação em águas abertas, hipip; akô, insistró, kagót, peikran, corrida de fundo, outros); atividades lúdicas para recreios e intervalos 
escolares; desenvolvimento de brincadeiras; brinquedos e brinquedotecas; maratonas escolares; olimpíadas esportivas; dentre outros;

- Produções técnicas, manutenção de infraestrutura e outras onde se destacam produtos como atualização de acervo da biblioteca escolar; criação de fóruns de licenciatura e formação docente; criação de laboratórios portáteis para o ensino de ciências; desenvolvimento de projetos sociais; manutenção de ateliê para atividades artísticas na escola; plano de melhoramento para laboratórios de ciências; revitalização de laboratórios de informática; modificação de projetos pedagógicos da licenciatura; criação de novas modalidades de licenciatura; criação de licenciaturas indígenas e do campo; criação de licenciaturas interculturais; outros produtos.

Esta técnica facilitou o manuseio dos relatórios, bastante extensos, e nos proporcionou não somente descrever os dados dos documentos, mas interpretá-los a partir da relação das características que observamos na organização das atividades, relacionadas ao uso de jogos e atividades lúdicas, no subprojeto Química sede do PIBID/UFRPE.

\section{Resultados e discussão}

A primeira categoria diz respeito à produção didático-pedagógica. Cada produto encontrado nos relatórios foi denominado aqui de subcategorias. Realizou-se a análise dos jogos, de acordo com a descrição desses pelos bolsistas dentro de cada subcategoria. De acordo com Souza e Machado (2018), o uso de sequências didáticas na educação vem ganhando destaque em pesquisas acadêmicas, como uma estratégia promissora para a formação docente. Para os autores, as Sequências Didáticas (SD) colaboram para a construção e reflexão da prática pedagógica dos professores, na qual são mobilizados o saber (logos) e o saber fazer (práxis) em sala de aula.

Em 2016 foi criada uma SD para abordar o assunto de Hidrocarbonetos. Em seu cronograma foram planejados quatro momentos, entre os meses de agosto e setembro, para a execução da SD onde estava previsto uma aula expositiva sobre petróleo e seus derivados, uma experimentação com gasolina aditivada e a exibição de um vídeo sobre o caminho da gasolina, numa segunda aula. O terceiro momento foi reservado para aplicação de um jogo com questionários e diversos desafios relativos ao tema estudado. Por último, foi planejada a aplicação de um questionário. No planejamento desta SD não estava especificado qual jogo seria utilizado, porém, ao analisarmos o relatório percebemos que se trataria do jogo "Trilha Química”, descrito mais à frente.

Em 2017, foi realizada uma SD para estimular os estudantes a desenvolverem práticas alimentares saudáveis, através de atividades com leitura e interpretação de textos, atividades lúdicas no laboratório de informática, aula prática no laboratório, exibição de vídeo, palestra com nutricionista, análise de rótulos de alimentos e produção e degustação de receitas saudáveis. As atividades lúdicas mencionadas não foram descritas no relatório. 
Ainda em 2017, os modelos atômicos foram estudados através de uma SD onde, num primeiro momento, houve um debate com os estudantes sobre suas concepções prévias quanto aos átomos. Num segundo momento, os bolsistas explicaram os modelos atômicos e como foi a evolução histórica do conceito de átomos e, no terceiro momento, foi proposto o jogo intitulado “Que modelo?! Qual situação?!”, consistindo em situações do cotidiano e qual modelo atômico explicaria cada uma. Os alunos deveriam fazer as ligações e explicar o porquê de sua escolha. Como, por exemplo: Que modelo justificaria as cores nos fogos de artifícios?

Quanto a subcategoria banner, foram gerados sete produtos que foram apresentados em eventos científicos nos anos de 2014 e 2016 e, por esse motivo, entendemos que deveriam constar na categoria das produções bibliográficas, porém, como a CAPES considera produção didático-pedagógica no âmbito do PIBID, vamos analisá-lo como parte desta categoria.

Em 2014, três dos quatro banners foram apresentados na XIV Jornada de Ensino, Pesquisa e Extensão da UFRPE (JEPEX), com os títulos, "Um jogo didático no ensino de reações químicas", "Construindo o conceito de ácidos e bases de Arrhenius utilizando um jogo de cartelas" e "Análise de jogos didáticos produzidos por alunos: quais os níveis de interação entre jogador e jogo?”.

O primeiro trata da utilização de um jogo para abordagem do tema reações químicas, onde foram confeccionadas 36 cartas, das quais 18 eram referentes às substâncias reagentes e as outras 18 por substâncias produtos das reações químicas, contendo figuras e fórmulas. A turma foi dividida em grupos que tinham que associar os reagentes aos produtos das reações químicas do cotidiano. O segundo banner tratava da aplicação de um jogo de cartelas para a formação das estruturas de ácidos e bases segundo a definição de Arrhenius. A estrutura de aplicação dos dois jogos apresentados nesses banners é a mesma, tendo em vista que ambos foram aplicados no âmbito de um projeto de confecção e aplicação de jogos do PIBID/UFRPE junto a uma turma do $2^{\circ}$ ano, no contra turno de uma escola estadual de referência em ensino médio localizada no Recife/PE.

O trabalho apresentado no terceiro banner do XIV JEPEX teve como objetivo analisar jogos didáticos, produzidos por alunos, envolvendo conteúdos químicos. Os jogos didáticos analisados foram produzidos por 30 alunos da $1^{\text {a }}$ série do ensino médio de uma escola pública, localizada em Recife/PE, sob a orientação de bolsistas do PIBID de Química, que discutiram com os alunos o conceito de jogo didático e apresentaram o programa Kurupira para produção de Palavras-Cruzadas. Em seguida, os alunos foram divididos em cinco grupos e receberam os materiais necessários para a produção dos jogos didáticos. Foram produzidos três jogos de tabuleiro e um Quebra-Cabeça. Os jogos didáticos de tabuleiro foram denominados pelos grupos como "Brincando com a Tabela" (Jogo 1), “Jogo da Química” (Jogo 2), e "Seja Nobre” (Jogo 3) e trataram do conteúdo Tabela Periódica dos Elementos. O jogo de Quebra-Cabeça abordou o Diagrama de Linus Pauling (Jogo 4). Posteriormente, os grupos apresentaram os jogos didáticos produzidos. 
O outro banner, produzido em 2014, foi apresentado no III Simpósio de Iniciação à Docência, com o título "Pergunte ao Químico: Abordagem de Propriedades Periódicas dos Elementos Através de Jogo Didático". O trabalho consistiu em um jogo de perguntas e respostas elaboradas pelos próprios alunos sobre a tabela periódica dos elementos e teve como objetivo despertar a criatividade dos alunos na confecção de jogos didáticos. Além do banner, esse jogo (Pergunte ao Químico) também foi relacionado nas categorias banco de imagens, plano de aula e publicação de resumos.

Em 2016, foi apresentado o banner sob o título "Estratégias Didáticas sobre Ligações Químicas para Alunos em Progressão com o Uso do Jogo Dado Químico" no VII Encontro Regional da SBQ3 Nordeste. Nesse trabalho, o objetivo era desenvolver o acompanhamento escolar para avaliação dos alunos em progressão, através de uma intervenção didática com o uso de jogos didáticos. Os bolsistas concluíram que é possível contribuir para a aprendizagem dos alunos em progressão, de forma lúdica, estimulandoos a participarem de atividades coletivas em sala de aula.

O jogo Trilha Química foi utilizado como parte de uma SD para trabalhar os conteúdos de Hidrocarbonetos e Petróleo e, foi inserido no relatório como plano de aula. O planejamento da SD foi feito a partir de uma aula expositiva sobre petróleo e seus derivados, experimentação e exibição de vídeo, jogo didático e aplicação de questionário. No momento do plano, o jogo não havia sido “batizado", porém, observou-se como se deu a aplicação da SD e os seus resultados, através de banner apresentado no XVI JEPEX, com o título "Aplicação de uma sequência didática sobre Hidrocarbonetos e Petróleo para resolução de uma situação problema". "Trilha Química" consiste em percorrer um caminho, onde os estudantes participavam de seis jogos lúdicos (perguntas, revisão, jogo da memória, desafio, pescando hidrocarbonetos, verdadeiro ou falso), integrando os conhecimentos químicos e processos de produção, utilização e reciclagem de matériasprimas à responsabilidade de preservação socioambiental. De acordo com os autores, os desafios sugeridos pela situação-problema e os elementos constituintes da SD ajudaram os alunos a alcançarem a aprendizagem de forma organizada e dialética.

O jogo Cara a Cara foi apresentado no XVI JEPEX, na forma de banner, com o título de "Jogo didático como método alternativo para o ensino de Química Orgânica". o jogo foi montado pelos estudantes com auxílio dos bolsistas usando materiais de baixo custo para confeccionar cartas com perguntas e respostas abordando o conteúdo de Hidrocarbonetos. Percebemos aqui que foram realizadas duas atividades com jogos de pergunta e resposta para estudar Hidrocarbonetos. Para Oliveira et al. (2013), este tipo de atividade mostra-se como uma boa estratégia de ensino tendo em vista que, além de ser um material simples e de baixo custo, estimula os estudantes a relacionar os conhecimentos adquiridos com os novos conhecimentos, tornando os alunos sujeitos ativos no processo de ensino e aprendizagem, além de tornar as aulas mais atrativas.

\footnotetext{
${ }^{3}$ SBQ: Sociedade Brasileira de Química.
} 
Além do plano de aula do jogo Trilha Química, realizado em 2016, esta subcategoria traz mais três produtos em 2014, dois deles fazem referência aos jogos Pergunte ao Químico e o Jogo de Cartelas, para estudar os conceitos de ácidos e bases de Arrhenius, mencionados acima na subcategoria banner. O outro plano de aula de 2014 trata do conceito de volatilidade, através de atividades lúdicas e experimentação.

Outra subcategoria relatada foram os Objetos de Aprendizagem (OA), Carneiro e Silveira (2014) definem um OA como:

quaisquer materiais eletrônicos (como imagens, vídeos, páginas web, animações ou simulações), desde que tragam informações destinadas à construção do conhecimento (conteúdo autocontido), explicitem seus objetivos pedagógicos e estejam estruturados de tal forma que possam ser reutilizados e recombinados com outros objetos de aprendizagem (padronização) (CARNEIRO; SILVEIRA, 2014, p. 239).

As autoras explicam ainda que diversos autores relacionam o conceito de $\mathrm{OA}$ ao uso de materiais digitais e apontam características como interatividade e reusabilidade. No Quadro 1, elas destacam sete condições para que um determinado recurso educacional seja considerado um objeto de aprendizagem.

Quadro 1. Condições para um recurso educacional ser considerado um OA.

\begin{tabular}{|l|l|}
\hline \multicolumn{1}{|c|}{ Condição } & \multicolumn{1}{c|}{ Detalhamento } \\
\hline $\begin{array}{l}\text { Explicitar claramente um } \\
\text { objetivo pedagógico }\end{array}$ & $\begin{array}{l}\text { Propiciar orientações claras para que o aluno saiba o que se espera que } \\
\text { ele aprenda ao usar o objeto de aprendizagem e o professor (distinto de } \\
\text { quem produziu o objeto) saiba como poderia usar o mesmo. }\end{array}$ \\
\hline Priorizar o digital & $\begin{array}{l}\text { Priorizar o desenvolvimento de objetos de aprendizagem que não } \\
\text { necessitem, para sua utilização, de aplicativo ou programa que não } \\
\text { esteja disponível gratuitamente na web. }\end{array}$ \\
\hline $\begin{array}{l}\text { Prover auxílio aos } \\
\text { usuários }\end{array}$ & $\begin{array}{l}\text { Oferecer auxílio ao usuário via interface e via instruções facilmente } \\
\text { acessíveis. }\end{array}$ \\
\hline $\begin{array}{l}\text { Proporcionar } \\
\text { interatividade }\end{array}$ & $\begin{array}{l}\text { Proporcionar que o usuário possa interagir, executando ações com o } \\
\text { objeto. }\end{array}$ \\
\hline Proporcionar interação & Permitir ações entre os usuários (alunos, professores, tutores etc.) \\
\hline $\begin{array}{l}\text { Fornecer feedback } \\
\text { constante }\end{array}$ & $\begin{array}{l}\text { Manter o usuário sempre informado do estado atual de sua interação } \\
\text { com o OA. }\end{array}$ \\
\hline Ser autocontido & $\begin{array}{l}\text { Ter foco em um determinado assunto e o explicar sem necessariamente } \\
\text { depender de outros objetos e/ou materiais. }\end{array}$ \\
\hline
\end{tabular}

Fonte: Carneiro e Silveira (2014).

Em 2016 foram relatados três objetos de aprendizagem com dois jogos, um jogo da memória com 8 peças, sendo quatro delas com os modelos atômicos mais conhecidos e as outras quatro com seus respectivos cientistas como indica a Figura 1, o objetivo era relacionar os cientistas aos seus modelos atômicos. 
Figura 1. Jogo da memória com modelos atômicos.

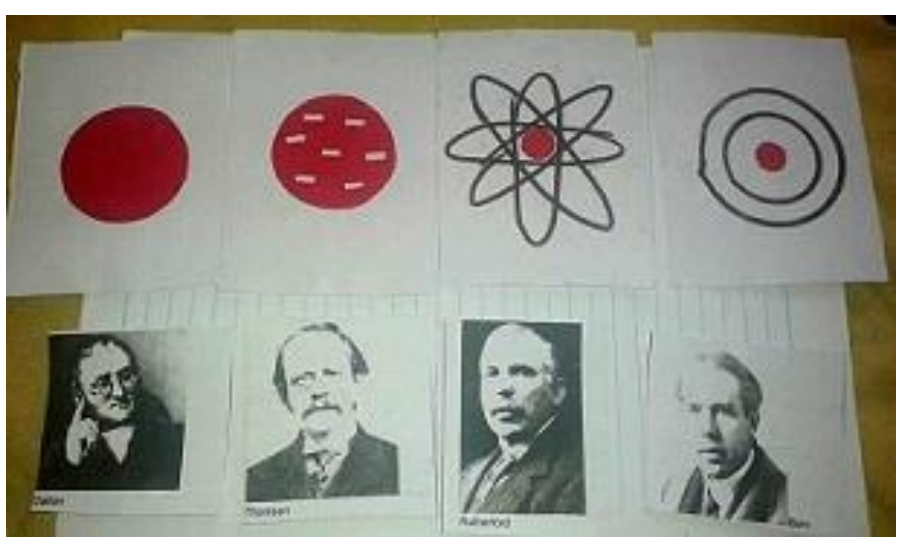

Fonte: Relatório final 2016 (PIBID/UFRPE).

Outro jogo apresentado como OA foi o jogo denominado "Quem sou eu", inspirado no jogo Cara a Cara, elaborado a partir de dicas que dão subsídios para se descobrir sobre algum objeto. Esse jogo foi adaptado tanto para o conteúdo de radioatividade, quanto para o de hidrocarbonetos.

Considerando as características elencadas no Quadro 1, observamos que os dois jogos relatados como OA não se enquadram como tal, tendo em vista que não se adéquam às características de "priorizar o digital", já que não foram disponibilizados em nenhuma plataforma; "prover auxílio aos usuários", pois, suas instruções não foram disponibilizadas em nenhuma interface, além disso, o jogo da memória com modelos atômicos não é "autocontido", porque para usá-lo os alunos precisam estudar o tema através de outros materiais.

Foi também produzido um caça-palavras como material didático para o ensino de hidrocarbonetos, com uma turma do $3^{\circ}$ ano, onde a turma foi dividida em grupos e com o auxílio dos bolsistas cada grupo criou o seu caça-palavras. Ramos (2006) explica que os documentos oficiais que deveriam nortear a educação nacional, não trazem a definição dos conceitos de recurso ou material didático e tratam o tema superficialmente. Rangel (2005) define material didático como qualquer instrumento utilizado para fins de ensino e aprendizagem. Nesse aspecto, concordamos com Santos (2014), quando ele considera material didático não apenas o recurso disponível, mas também a proposta didática do professor. Os bolsistas do PIBID, ao estimularem os alunos a criarem caça-palavras, estão criando uma ponte entre a teoria e a prática, tornando-os sujeitos ativos no processo de ensino e aprendizagem. Muito embora a produção de material didático não esteja elencada 
no rol das categorias da CAPES, consideramos essa prática importante ação dentro do programa, pois, colaborou com a formação de futuros professores engajados em produzir seus próprios materiais didáticos.

A subcategoria estratégia didática traz um jogo de palavras cruzadas para abordar a conceituação e aplicação da química e outro jogo não especificado no relatório, criado pelos bolsistas de Química para trabalhar o conteúdo de ligações químicas.

A subcategoria jogos é mais uma que não figura de forma explícita no rol da produção da CAPES e conta com cinco produtos gerados, em 2015 e 2017.

Em 2015 foram relatados três jogos e, embora o objetivo descrito seja "desenvolver jogos para auxílio no processo ensino-aprendizagem de Química", os três produtos relatados são oriundos de jogos já existentes e que foram adaptados para a realidade local. Em uma destas atividades, os bolsistas fizeram uso do jogo didático online Adivinhas para abordagem de conteúdos sobre a tabela periódica. Segundo Santos (2014) este jogo averigua se o jogador consegue, através de dicas, descobrir qual o elemento químico em questão. Outra atividade, que relacionou os jogos com o uso de tecnologia, foi um jogo de perguntas e respostas em que os bolsistas projetavam as perguntas para revisão de conteúdos diversos em Data-Show, para que os alunos respondessem com as placas código as alternativas que julgavam corretas. Para avaliação dessa atividade foi utilizado o aplicativo "plickers" que, de acordo com Nunes e Couto (2017), tem como objetivo possibilitar uma avaliação dinâmica, capaz de medir instantaneamente o aprendizado. Por último, foi utilizado o jogo qui(mico) que é um material de cartas que tem como objetivo associar as funções de Química Orgânica com seus respectivos grupos funcionais.

Em 2017, o jogo denominado Química News, surgiu de um projeto interdisciplinar entre bolsistas da Química e da Licenciatura em Computação para desenvolvimento de um jogo com o uso da tecnologia do aplicativo Inventor $2^{4}$. 0 jogo, desenvolvido para alunos do ensino médio e para pessoas que apresentam dificuldades com a Química, utiliza figuras relacionadas aos elementos químicos com perguntas objetivas referentes às aplicações e reações entre os elementos químicos em questão. Trata-se de um jogo de celular, com perguntas e respostas sobre a tabela periódica.

O uso de dispositivos móveis, como smartphones e tablets, vem sendo cada vez mais comum em sala de aula, de acordo com o relatório do Horizont Report (Johnson et al., 2014), que tem como objetivo identificar e descrever as tecnologias emergentes que impactam a educação em todo o planeta, apontando, em sua edição de 2014, os games, tablets e dispositivos móveis, como importantes mídias que trarão maior impacto para esse setor nos próximos três anos.

\footnotetext{
4 O App Inventor é um software web criado pela universidade americana Massachusetts Institute of Technology (MIT) que permite desenvolver aplicativos Android usando um navegador da Web e um telefone ou emulador conectados.
} 
Ao realizarem levantamento quanto ao uso de jogos móveis, Barbosa e Pio (2018) observaram que a maioria das publicações relativas à jogos móveis no Brasil, se concentra em outras áreas que não a de ciências. Tal constatação demonstra que apesar do PIBID levar para os bolsistas experiências com novas tecnologias e tendências na educação, os jogos, a partir de dispositivos móveis, poderiam ser mais explorados tendo em vista seus benefícios para os processos de ensino e aprendizagem.

Outro produto relatado na categoria jogos foi a construção de um modelo molecular alternativo, usando jujubas e palitos de dente. Esta atividade lúdica teve como objetivo a compreensão das diferentes geometrias das moléculas, baseada no modelo VSEPR 5 , a partir de uma visualização 3D. Destacamos aqui, o uso de material de baixo custo, defendido por Soares (2004).

Foram produzidos três slides, destes, dois foram confeccionados para apresentar na culminância do ano de 2017, onde foram citadas as atividades com caça-palavras para estudar química orgânica e o aplicativo Química News. O terceiro foi produzido para apresentar o trabalho intitulado de "Palavras cruzadas: uma estratégia para o ensino de funções orgânicas", apresentado no $1^{\circ}$ Seminário Estadual do PIBID e PIBID Diversidade.

A subcategoria produção de software traz um material de apoio para o desenvolvimento do aplicativo Química News abordado acima. Entre os relatos de experiência, duas bolsistas mencionaram o uso de jogos em suas atividades no ano de 2017, porém, não especificaram os jogos utilizados. Já o banco de imagens é usado para mostrar os registros fotográficos feitos pelos alunos em atividade no Pibid. A Figura 1 é um exemplo de registros encontrados nessa subcategoria.

O Gráfico 1 representa a produção didático-pedagógica e as subcategorias que emergiram, a partir do uso de jogos e atividades lúdicas, no subprojeto Química Sede do PIBID/UFRPE.

\footnotetext{
${ }^{5}$ É uma sigla inglesa VSEPR (vésper), significando Valence Shell Electron Pair Repulsion (repulsão eletrônica entre os pares de elétrons na camada de valência). Em alguns livros texto é utilizada a sigla REPECV.
} 
Gráfico 1. Produção Didático-Pedagógica.

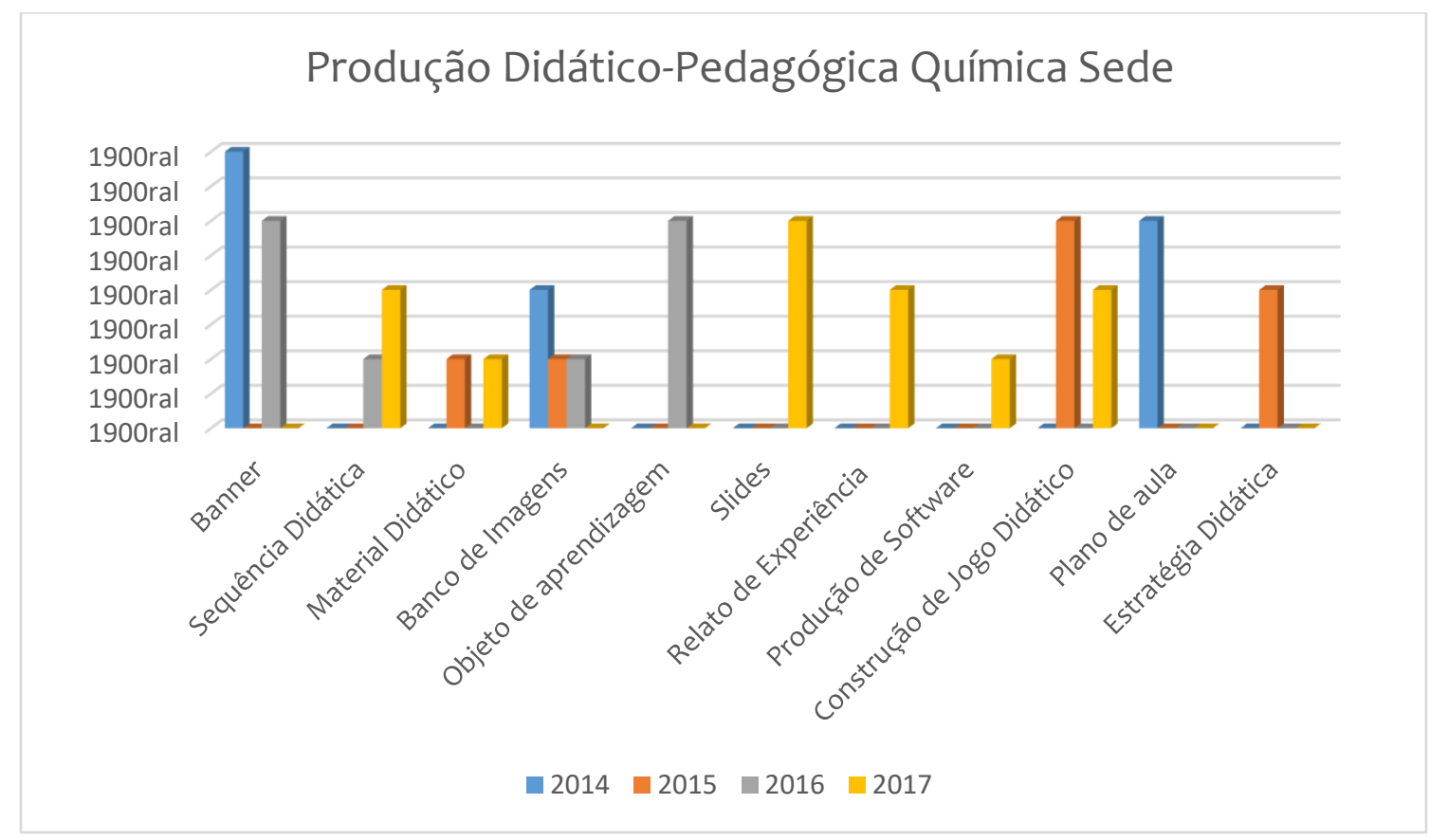

Fonte: Relatórios de atividades do PIBID/UFRPE, subprojeto Química Sede (2014, 2015, 2016, 2017).

A partir do Gráfico 1, observamos que a produção didático-pedagógica dos bolsistas gerou 35 produtos relacionados ao uso de jogos divididos em 11 subcategorias. Esta produção abordou conceitos da Química, como ligações químicas, hidrocarbonetos, funções orgânicas, bioquímica dos alimentos, modelos atômicos, tabela periódica, estruturas moleculares, reações químicas, ácidos e bases, distribuição eletrônica, volatilidade e radioatividade, além de revisões de temas variados, a partir da criação ou adaptação de jogos e atividades lúdicas. A quantidade de subcategorias demonstra a versatilidade dos jogos no ensino de Química, tendo em vista que eles foram utilizados de várias formas.

Parte dessa produção didático-pedagógica conduziu à elaboração de cinco investigações sobre essas ações. Esses estudos foram divulgados em forma de publicações em resumos fixados em anais de eventos locais e regionais, fazendo parte da categoria produção bibliográfica.

Em 2014 foi publicado resumo no III Simpósio de Iniciação à Docência (SID) da UFRPE com o título "Pergunte ao químico: abordagem de propriedades periódicas dos elementos através de jogo didático", além do trabalho publicado na XIV Jornada de Ensino e Pesquisa (JEPEX) intitulado "Ludo químico: produção de jogos didáticos por alunos no clube da Química". 
Em 2016 foram publicados os trabalhos "Jogo didático como método alternativo para o ensino de Química Orgânica”, na XVI JEPEX, e no $7^{\circ}$ SBQ Nordeste, o trabalho "Estratégia Didática sobre Ligações Químicas para alunos em Progressão com o Uso do Jogo Dado Químico". Já em 2017, o trabalho "Palavras cruzadas: uma estratégia para o ensino de funções orgânicas" foi publicado no I Seminário PIBID e PIBID Diversidade, sede Pernambuco.

A participação dos bolsistas em eventos científicos é considerada muito importante, tendo em vista que leva os graduandos ao exercício da investigação científica, além de proporcionar a troca de experiências, enriquecendo sua formação docente.

Quanto às outras três categorias (produção artístico-cultural; produção desportiva e lúdica; e produções técnicas, manutenção de infraestrutura e outras), não identificamos registros nos relatórios analisados. Sendo assim, as duas categorias analisadas geraram um total de 40 produtos relacionados aos jogos e atividades lúdicas, distribuídos em 12 subcategorias. O conceito mais explorado nessa produção foi o de Hidrocarbonetos, seguido dos estudos sobre a tabela periódica. O Gráfico 2 traz um resumo dos conceitos trabalhados.

Gráfico 2. Conceitos abordados através de jogos no PIBID Química sede UFRPE.

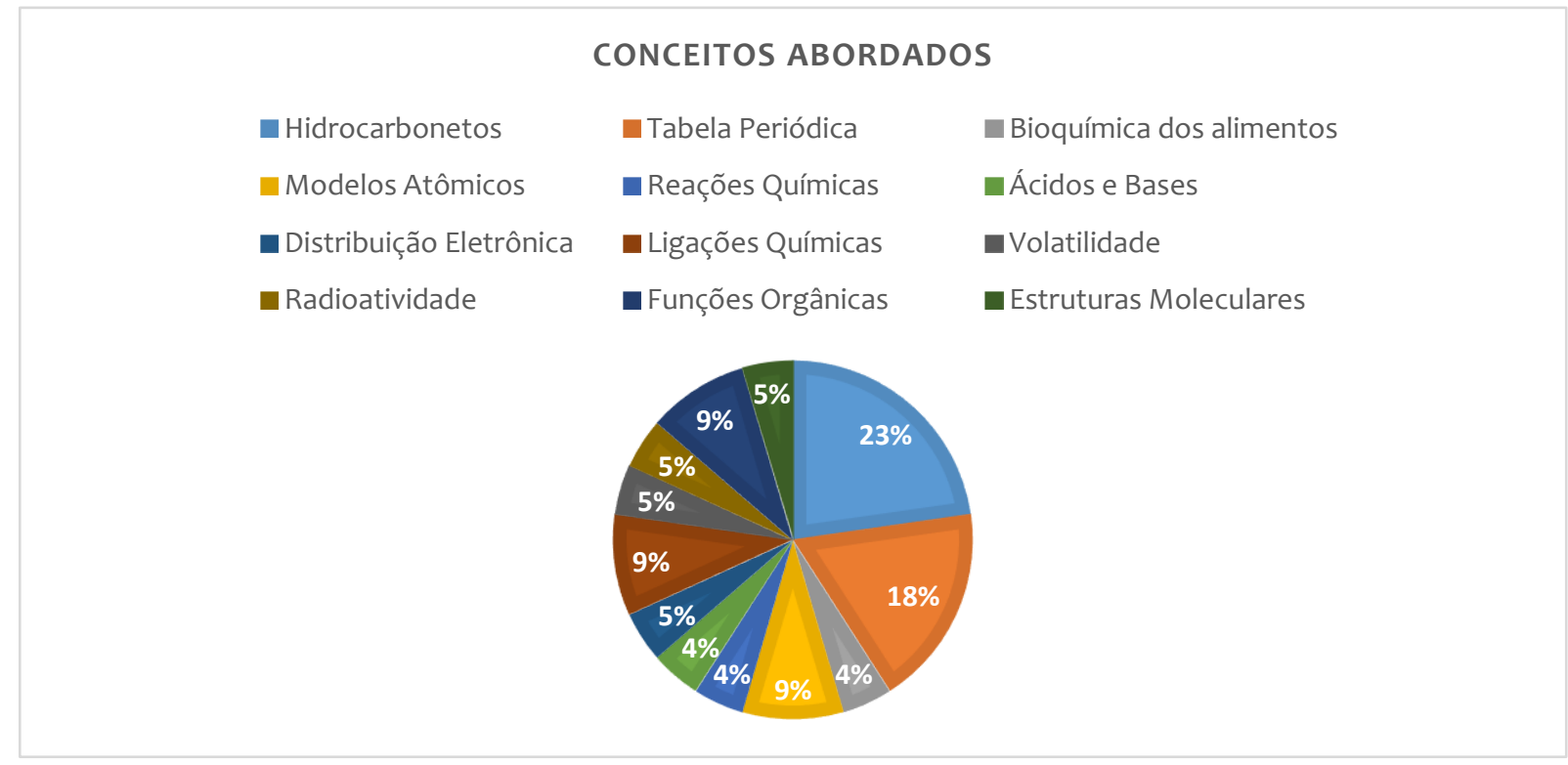

Fonte: Relatórios de atividades do PIBID/UFRPE, subprojeto Química Sede (2014, 2015, 2016, 2017).

Quanto à classificação dos jogos, Lara (2005) utiliza-se dos objetivos propostos. Segundo a citada autora, os jogos de construção são aqueles que trazem aos alunos um assunto desconhecido e, através da dinâmica deste jogo, faz com que eles sintam a necessidade de adquirir um novo conhecimento para resolver uma situação problema. Os jogos de treinamento são aqueles que auxiliam os alunos a abstrair os conhecimentos construídos, através da repetição de exercícios, sendo usados para verificar o que eles aprenderam. Os jogos de aprofundamento são aqueles que permitem que os alunos 
apliquem o conhecimento construído, através de jogos que aumentem a complexidade gradualmente, de forma a exigir que eles busquem novos conhecimentos. Os jogos estratégicos são aqueles que fazem com que os educandos criem estratégias de ação, para que melhorem sua atuação como jogador, criando hipóteses e desenvolvendo um pensamento sistêmico, dentro do tema abordado pelo jogo.

Considerando esta classificação, embora os relatórios não sejam tão claros quanto aos objetivos das atividades lúdicas e jogos utilizados, foi possível constatar que, apesar dos quatro tipos de jogos terem sido encontrados, há uma predominância do uso de jogos de treinamento, ou seja, a maioria das atividades com jogos foram realizadas com o objetivo de revisar assuntos já estudados. Segundo Soares (2010), jogos que consideram o raciocínio dos alunos e o ensino-aprendizagem de um conceito são mais difíceis de serem propostos em sala de aula. Nesse sentido, é interessante que os bolsistas possam se aprofundar um pouco mais nas teorias de jogos para que possam aplicar essa ferramenta de forma mais abrangente, durante suas atuações no programa e, futuramente, em suas vidas profissionais.

Outro aspecto importante a ser destacado é que dois jogos foram aplicados de forma interdisciplinar, oportunizando aos bolsistas [por meio do uso de jogos] extrapolarem os limites da sua disciplina e a trocarem experiências com bolsistas de outras áreas.

\section{Considerações finais}

De acordo com os resultados obtidos, observou-se que os jogos puderam ser utilizados a partir de estratégias variadas, porém, com ênfase na revisão de conceitos abordados. Os materiais utilizados variaram, desde os materiais de baixo custo até o uso de jogos online. Percebeu-se nos relatórios que a maior parte das atividades lúdicas e jogos relatados, não fizeram uma associação mais profunda entre a teoria e a prática, posto que, quase todos os relatos tratam da execução das atividades sem um maior aprofundamento acerca das teorias dos jogos.

No que diz respeito aos relatórios observamos que os critérios adotados pela CAPES para definir as categorias dessas produções do PIBID deveriam ser mais claros e bem definidos, de forma a facilitar a análise destes.

Por fim, outro aspecto observado foi a função motivacional dos jogos e atividades lúdicas utilizadas, verificando-se que estes criam estímulo e o ambiente necessário para possibilitar o desenvolvimento, de forma espontânea e criativa dos alunos, além de propiciar que os bolsistas de iniciação à docência aumentem seus conhecimentos sobre técnicas significativas e diferenciadas de ensino e desenvolvam suas capacidades profissionais, estimulando-os a criar sua própria prática pedagógica. 


\section{Referências}

BARBOSA, M. S.; PIO, J. L. S. Jogos móveis como ferramenta na aprendizagem colaborativa: uma revisão sistemática da literatura. In: CONGRESSO NACIONAL DE PESQUISA E ENSINO EM CIÊNCIAS, 3, 2018, Campina Grande/PB. Anais eletrônicos... Campina Grande/PB: Realize, 2018.

BARDIN, L. Análise de conteúdo. Lisboa: Edições 70, 1977.

CARNEIRO, M. L. F.; SILVEIRA, M. S. Objetos de Aprendizagem como elementos facilitadores na Educação a Distância. Educar em Revista, Edição Especial, n. 4, 2014, p. 235-260.

CUNHA, M. B. Jogos no ensino de Química: considerações teóricas para sua utilização em sala de aula. Revista Química Nova na Escola, São Paulo, v. 34, n. 2, 2012, p. 92-98.

JOHNSON, L. et al. NMC Horizon Report: Higher education edition. Austin, Texas: The New Media Consortium, 2014.

KISHIMOTO, T. M. O brincar e suas teorias. São Paulo/SP: Pioneira, 1998.

. Jogo, Brinquedo, Brincadeira e a Educação. São Paulo/SP: Cortez, 2002.

. O jogo e a educação infantil. São Paulo/SP: Pioneira, 2003.

LARA, I. C. M. Jogando com a matemática. São Paulo/SP: Rêspel, 2005.

NUNES, V. W. N.; COUTO, R. R. Uso do aplicativo plickers dentro da proposta de Metodologia ativa. In: CONGRESSO INTERNACIONAL ABED DE EDUCAÇÃO A DISTÂNCIA, 2017, Foz do Iguaçu. Anais eletrônicos... Foz do Iguaçu: ABED, 2017.

Disponível em:< http://www.abed.org.br/congresso2017/trabalhos/pdf/243.pdf>. Acesso em: 04 jun. 2019.

OLIVEIRA, D. A.; GHEDIN, E.; SOUZA, J. M. O jogo de perguntas e respostas como recurso didático-pedagógico no desenvolvimento do raciocínio lógico enquanto processo de ensino aprendizagem de conteúdos de ciências do oitavo ano do ensino fundamental. In: ENCONTRO NACIONAL DE PESQUISA EM EDUCAÇÃO EM CIÊNCIAS, 2013, Águas de Lindóia/SP. Anais eletrônicos... Águas de Lindóia/SP: ABRAPEC, 2013.

Disponível em:< http://www.nutes.ufrj.br/abrapec/ixenpec/atas/resumos/R1434-1.pdf>. Acesso em: 04 jun. 2019.

RAMOS, F. C. O livro e os recursos didáticos no ensino de Matemática. 2006. Dissertação (Mestrado Profissionalizante em Ensino de Física e Matemática) - Centro Universitário Franciscano de Santa Maria. Santa Maria/RS, 2006.

RANGEL, E. O. Avaliar para melhor usar - avaliação e seleção de materiais e livros didáticos. In: BRASIL. MEC. Salto para o Futuro.TV Escola: Materiais didáticos: escolha e uso. Boletim 14, agosto 2005.

Disponível em: <http://tvbrasil.org.br/fotos/salto/series/151007MateriaisDidaticos.pdf>. Acesso em: 21 mar. 2019. 
SANTOS, M. C. A importância da produção de material didático na prática docente. In: CONGRESSO BRASILEIRO DE GEÓGRAFOS, 2014, Vitória. Anais eletrônicos.... Vitória/ES: AGB, 2014.

SILVA, A. R. M. R. et al. PIBID Reflexões Teóricas e Vivências Formativas. Recife/PE: EDUFRPE, 2017.

SOARES, M. H. F. B. O lúdico em Química: jogos e atividades aplicados ao ensino de química. 2004. 203f. Tese (Doutorado em Ciências: Química)- Centro de Ciências Exatas e de Tecnologia, Universidade Federal de São Carlos. São Carlos/SP, 2004.

SOARES, M. H. F. B. et al. Jogos em ensino de química: Avaliação da produção científica a partir dos trabalhos publicados nos encontros nacionais de ensino de química (período 1996 a 2008). In: ENCONTRO NACIONAL DE ENSINO DE QUÍMICA, 2010, Brasília/DF. Anais Eletrônicos... Brasília/DF: SBQ, 2010.

SOARES, M. H. F. B et al. (Orgs.). Didatização lúdica no ensino de química/ciências: teorias de aprendizagem e outras interfaces. São Paulo/SP: Livraria da Física, 2018.

SOUZA, E. O.; MACHADO, V. M. Sequência didática no processo de formação inicial de professores de Ciências Biológicas. Revista de Ensino de Biologia da SBEnBio, v. 11, n. 2, 2018, p. 77-84. Disponível em:< http://sbenbio.journals.com.br/index.php/sbenbio/article/view/176> . Acesso em: 13 fev 2019. 